\title{
Predictors of quality of life among hospitalized geriatric patients with diabetes mellitus upon discharge
}

Nuruljannah Johari'

Zahara Abdul Manaf'

Norhayati Ibrahim ${ }^{2}$

Suzana Shahar'

Norlaila Mustafa ${ }^{3}$

'Dietetics Programme, ${ }^{2} \mathrm{Health}$ Psychology Programme, Faculty of Health Sciences, ${ }^{3}$ Medical Department, Faculty of Medicine, Hospital Canselor Tuanku Muhriz, Universiti Kebangsaan Malaysia, Kuala Lumpur, Malaysia
Correspondence: Zahara Abdul Manaf Dietetics Programme, Faculty of Health Sciences, Universiti Kebangsaan Malaysia, Jalan Raja Muda Abdul Aziz, 50300 Kuala Lumpur, Malaysia

Email zaharamanaf@ukm.edu.my
This article was published in the following Dove Press journal:

Clinical Interventions in Aging

17 October 2016

Number of times this article has been viewed

Purpose: Diabetes mellitus is prevalent among older adults, and affects their quality of life. Furthermore, the number is growing as the elderly population increases. Thus, this study aims to explore the predictors of quality of life among hospitalized geriatric patients with diabetes mellitus upon discharge in Malaysia.

Methods: A total of 110 hospitalized geriatric patients aged 60 years and older were selected using convenience sampling method in a cross-sectional study. Sociodemographic data and medical history were obtained from the medical records. Questionnaires were used during the in-person semistructured interviews, which were conducted in the wards. Linear regression analyses were used to determine the predictors of each domain of quality of life.

Results: Multiple regression analysis showed that activities of daily living, depression, and appetite were the determinants of physical health domain of quality of life $\left(R^{2}=0.633\right.$, $F(3,67)=38.462 ; P<0.001)$, whereas depression and instrumental activities of daily living contributed to $55.8 \%$ of the variability in psychological domain $\left(R^{2}=0.558, F(2,68)=42.953\right.$; $P<0.001)$. Social support and cognitive status were the determinants of social relationship $\left(R^{2}=0.539, F(2,68)=39.763 ; P<0.001\right)$ and also for the environmental domain of the quality of life $\left(R^{2}=0.496, F(2,68)=33.403 ; P<0.001\right)$.

Conclusion: The findings indicated different predictors for each domain in the quality of life among hospitalized geriatric patients with diabetes mellitus. Nutritional, functional, and psychological aspects should be incorporated into rehabilitation support programs prior to discharge in order to improve patients' quality of life.

Keywords: diabetes mellitus, geriatric, quality of life, hospitalized, rehabilitation

\section{Introduction}

In Malaysia, the elderly population is projected to increase from 1.4 million in 2000 to 3.4 million in $2020 .{ }^{1}$ This consequently increases the prevalence of those with illness, such as diabetes mellitus, which affects their quality of life. Although malnutrition, ${ }^{2}$ disabilities, ${ }^{3}$ and depression ${ }^{4}$ are prevalent among geriatric patients with diabetes mellitus, hospitalized geriatric patients suffer a gradual decline in their nutritional status. ${ }^{5}$ The decline in sense of smell and taste, ${ }^{6}$ other oral problems, ${ }^{7,8}$ and inability to buy or prepare foods lead to a decrease in appetite, thus resulting in the depletion of energy and nutrient intake. ${ }^{8}$

Geriatric patients with depression have lower global cognitive function and weaker verbal and memory learning performance as compared to those without depression. ${ }^{9}$ Depression in geriatric patients with diabetes also causes disability, ${ }^{3,10}$ decline of health, especially for those with chronic diseases, ${ }^{11}$ such as diabetes, and is closely 
associated with hyperglycemia, ${ }^{12}$ thus affecting the quality of life of patients. ${ }^{13,14}$

Functional status is an important viability factor among the elderly. ${ }^{15}$ Geriatric syndrome, such as incontinence, ${ }^{16}$ loss of hearing, ${ }^{17}$ and falls,,${ }^{18,19}$ is common among elderly and consequently affects their activities of daily living. Eventually, if their independency declines, they will be at high risk of malnutrition. ${ }^{20}$ As mentioned earlier, their functional status is also affected by depression and diabetes mellitus. ${ }^{3}$ Thus, this shows that nutritional and functional statuses and psychological health are related to each other and affect the quality of health of elderly with diabetes mellitus.

In addition, social support for geriatric patients with diabetes is important to help them deal with depression ${ }^{10}$ and improve their quality of life. ${ }^{13}$ Although knowledge about diabetes is not a determining factor of diabetes control, ${ }^{21,22}$ it still plays an important role in rehabilitation as it is found that awareness regarding diabetes is still lacking among most elderly patients. ${ }^{23}$ Nutritional, psychosocial, and physical rehabilitation support affects patients' rehabilitation process during hospitalization and even after the patient is discharged.

Elderly who received treatment with specialized assessment and management for geriatric patients showed a reduction in the deterioration of functionality, while being treated in hospital and also showed progress in terms of mental health when receiving outpatient treatment, without increasing the costs of treatment. ${ }^{24}$ However, little is known about predictors of quality of life among hospitalized geriatric patients with diabetes mellitus. Hence, this cross-sectional study was conducted to determine the predictors of the quality of life from various aspects among hospitalized geriatric patients with diabetes mellitus. The results from this study could provide some baseline data on nutritional, functional, and psychosocial aspects for future multidisciplinary intervention programs and implementation prior to discharge and postdischarge follow-up.

\section{Methods}

\section{Ethics statement}

This study was approved by the Secretariat for Research and Ethics of Universiti Kebangsaan Malaysia (UKM 1.5.3.5/244/NN-082-2014). Informed consent was obtained from all participants.

\section{Patients and design}

This cross-sectional study was conducted among hospitalized Malaysian geriatric patients aged at least 60 years at the time of their admission to Hospital Canselor Tuanku Muhriz, Cheras, from August 2014 to January 2015. In this study, a total of 110 geriatric patients were selected. However, only 71 patients completed the entire questionnaires. Patients who, 1) were unable to communicate well in Malay or English, 2) had terminal illness or were under palliative care, and 3) were diagnosed with psychiatric conditions, including schizophrenia and dementia, were excluded. The sociodemographic data and medical history were obtained from patients' medical records. The nutritional status, functional status, and neuropsychological status were assessed through in-person semistructured interviews. A script of simple colloquial questions was prepared since patients came from different ethnicities, linguistics, educational backgrounds, and socioeconomic statuses with different levels of literacy and cognitive function. Most of the questionnaires used were based on scales and optional answers. These may reduce interviewer bias to ensure more predictive decision.

\section{Assessment of nutritional, functional, and neuropsychological statuses and quality of life}

The appetite and nutritional statuses were assessed using the simplified nutritional appetite questionnaire ${ }^{25}$ and diet history questionnaire, ${ }^{26}$ respectively. The dietary intake was then analyzed using Nutritionist Pro $^{\mathrm{TM}}$. Neuropsychological performance was assessed using the Montreal Cognitive Assessment, ${ }^{27}$ Geriatric Depression Scale, ${ }^{28}$ and brief-illness perception questionnaire. ${ }^{29}$ Functional status was assessed based on eight modified Barthel Index items measuring disabilities in activities of daily living (ADL) ${ }^{30}$ and instrumental activities of daily living (IADL). ${ }^{31}$ The Medical Outcomes Study-Social Support Survey ${ }^{32}$ was used to assess social support received by the patients. Four different aspects of quality of life, physical health, psychological, social relationship, and environment, were measured using the World Health Organization Quality of Life-BREF-short version questionnaire. ${ }^{33}$

\section{Statistical analyses}

All statistical analyses were performed using SPSS software (Version 22.0; IBM Corporation, Armonk, NY, USA). The statistical significance was assessed at the level of 0.05 (two tailed) and $P$-value of $<0.05$. Chi-square test was used to differentiate between sex and demographic data for categorical data. Independent $t$-test or Mann-Whitney $U$-test was used to assess the relationship between sex and nutritional, functional, psychosocial statuses, and quality of life for numerical 
data. Pearson and Spearman correlations were used to measure the correlation of World Health Organization Quality of Life-BREF score with other continuous data. Independent variables with the highest correlation value with each domain of quality of life were adjusted into linear regression model. Multiple linear regression was used to identify the predictors of each domain in the quality of life. The enter method was used to assess the accuracy and stability of the model.

\section{Results}

A total of 110 patients $(53.6 \%[n=59]$ men and $46.4 \%[n=51]$ women) agreed to be interviewed and completed almost all of the questionnaires. The majority were Malays (65.5\%), married (70.9\%), living with others (90.9\%), and unemployed $(88.2 \%)$. The mean age of patients was $68 \pm 6.4$ years as shown in Table 1.

Table 2 shows that the mean body mass index for male and female patients were $26.3 \pm 4.9 \mathrm{~kg} / \mathrm{m}^{2}$ and $25.1 \pm 5.4 \mathrm{~kg} / \mathrm{m}^{2}$, respectively, with only $43.6 \%$ of the patients with normal body weight. Four patients were on tube feeding regime and $45.3 \%$ were at risk of at least $5 \%$ weight loss based on their appetite assessment. Of all the predictors assessed, only the Montreal Cognitive Assessment score showed significant difference between the male and female patients $(P<0.05)$. The results showed that $83 \%$ of patients had mild cognitive impairment (MCI).

Table I Sociodemographic profile of patients by sex

\begin{tabular}{|c|c|c|c|}
\hline \multirow[t]{2}{*}{ Variables } & \multicolumn{2}{|l|}{ Sex } & \multirow{2}{*}{$\begin{array}{l}\text { Total } \\
(\mathrm{N}=|\mathrm{I}| 0)\end{array}$} \\
\hline & $\begin{array}{l}\text { Male } \\
(n=59)\end{array}$ & $\begin{array}{l}\text { Female } \\
(n=5 I)\end{array}$ & \\
\hline \multicolumn{4}{|l|}{ Ethnicity } \\
\hline Malay & $39(66.1)$ & $33(64.7)$ & $72(65.5)$ \\
\hline Chinese & II (I8.6) & $12(23.5)$ & $23(20.9)$ \\
\hline Indian & $9(15.3)$ & $6(11.8)$ & $15(13.6)$ \\
\hline Age (years) & $68.7 \pm 6.3$ & $68.3 \pm 6.5$ & $68 \pm 6.4$ \\
\hline \multicolumn{4}{|l|}{ Marital status } \\
\hline Married & $5 I(86.4)^{*}$ & $27(52.9)$ & $78(70.9)$ \\
\hline Single/divorced & $8(13.6)$ & $24(47.1)$ & $32(29.1)$ \\
\hline \multicolumn{4}{|l|}{ Living arrangement } \\
\hline Alone & $6(10.2)$ & $4(7.8)$ & $10(9.1)$ \\
\hline With others & $53(89.8)$ & $47(92.2)$ & $100(90.9)$ \\
\hline \multicolumn{4}{|l|}{ Educational status } \\
\hline Primary school and below & $23(39.0)$ & $29(56.9)$ & $52(47.3)$ \\
\hline Secondary school and above & $36(61.0)$ & $22(43.1)$ & $58(52.7)$ \\
\hline \multicolumn{4}{|l|}{ Employment status } \\
\hline Unemployed/retired & $46(78.0)$ & $51(100.0)$ & $97(88.2)$ \\
\hline Working & $13(22.0)^{*}$ & $0(0.0)$ & $13(1 \mid .8)$ \\
\hline \multicolumn{4}{|l|}{ Main financial resources } \\
\hline Self-finance & 43 (72.9)* & $17(33.3)$ & $60(54.5)$ \\
\hline Others & $16(27.1)$ & $34(66.7)$ & $50(45.5)$ \\
\hline
\end{tabular}

Notes: Data are presented as $\mathrm{n}(\%)$ or mean \pm SD. $* P<0.05$, significant difference for chi-square test.
Multiple regression analysis showed that ADL, level of depression, and appetite were the predictors of physical health domain of the quality of life $\left(R^{2}=0.633\right.$, $F(3,67)=38.462, P<0.001)$. These parameters contributed to $63.3 \%$ of variability of the physical health domain. Depression and IADL contributed to $55.8 \%$ of variability in the psychological domain of the quality of life $\left(R^{2}=0.558\right.$, $F(2,68)=42.953, P<0.001)$. Social support received by the patients and cognitive status accounted for $53.9 \%$ of variability in the social relationship domain of the quality of life $\left(R^{2}=0.539, F(2,68)=39.763, P<0.001\right)$. Social support and cognitive statuses were also the predictors that accounted for $49.6 \%$ of the variability of environment domain of the quality of life $\left(R^{2}=0.496, F(2,68)=33.403\right.$, $P<0.001)$. The results from multiple linear regression test are shown in Table 3.

\section{Discussion}

In this study, the mean energy and protein intake indicated that patients did not achieve the recommended nutrient intake for Malaysia ${ }^{34}$ and their intake was lower as compared to community-dwelling elderly. ${ }^{35}$ Hospitalization can lead to deterioration of nutritional status. ${ }^{5}$ Other factors that lead to poor dietary intake during hospitalization are chewing difficulties related to dental problems, low calorie diet or fasting for medical procedures, and lack of assistance during feeding time. ${ }^{36}$ Food preferences, aversion to certain smells, and taste of the food served by the hospital were the most common complaints voiced by the geriatric patients. ${ }^{37}$ Insufficient food intake among patients is not predominantly caused by disease. ${ }^{38}$ Male, higher body mass index, modified dietary prescription, length of stay $<8$ days or $\geq 90$ days, and inadequate supper were reported as other risk factors that cause insufficient food intake during hospitalization. ${ }^{38}$

This study showed that $44.9 \%$ of patients were mild to severely depressed, which is much higher compared to other local studies that revolved around the community dwelling elderly. ${ }^{39-41}$ A study by Koenig ${ }^{42}$ found that $36.5 \%$ of the patients with chronic illness had major depression, which is significantly higher than those without chronic disease. They also require more inpatient and outpatient medical services and exhibit a prolonged state of depression even after being discharged. However, those with intrinsic religiosity require a shorter time for the remission of depression. ${ }^{43}$ Depression among geriatric patients on the ward is not only caused by health-related problems but also caused by nonhealthrelated problems, such as stressful life events, ${ }^{44}$ loneliness, ${ }^{45}$ 
Table 2 Nutritional, functional, psychological, and quality of life assessment of patients

\begin{tabular}{|c|c|c|c|c|c|}
\hline \multirow[t]{2}{*}{ Variables } & \multicolumn{4}{|c|}{ Sex } & \multirow[t]{2}{*}{$P$-value } \\
\hline & $\mathbf{n}$ & Male ( $\mathbf{N}=59)$ & $\mathbf{n}$ & Female $(\mathrm{N}=5 \mathrm{I})$ & \\
\hline BMI $\left(\mathrm{kg} / \mathrm{m}^{2}\right)$ & 59 & $26.3 \pm 4.9$ & 51 & $25.1 \pm 5.4$ & 0.205 \\
\hline HbAIC (\%) & 44 & $7.2 \pm 1.2$ & 35 & $7.8 \pm 1.6$ & 0.082 \\
\hline Duration of diabetes (years) & 59 & $16.3 \pm 10.0$ & 51 & $14.5 \pm 9.2$ & 0.354 \\
\hline SNAQ & 57 & $|4.7 \pm 3|$. & 49 & $13.6 \pm 3.7$ & 0.093 \\
\hline Calorie intake (kcal/d) & 59 & $|, 3| 3 \pm 340$ & 51 & $1,19 \mid \pm 334$ & $0.06 \mathrm{I}$ \\
\hline Protein intake $(\mathrm{g} / \mathrm{d})$ & 59 & $53 \pm 15$ & 51 & $50 \pm 14$ & 0.388 \\
\hline Barthel Index & 59 & $83.5 \pm 22.3$ & 51 & $80.3 \pm 24.5$ & 0.586 \\
\hline IADL & 59 & $3.5 \pm 1.6$ & 51 & $4.7 \pm 2.6$ & $\mathrm{~N} / \mathrm{A}$ \\
\hline The MoCA & 52 & $19.6 \pm 7.4$ & 42 & $14.9 \pm 6.7$ & $0.002 *$ \\
\hline $\mathrm{GDS}^{\mathrm{a}}$ & 58 & $4.2 \pm 3.8$ & 49 & $5.2 \pm 3.5$ & 0.087 \\
\hline B-IPQ & 54 & & 44 & & \\
\hline Total score & & $32.9 \pm 12.6$ & & $31.8 \pm 10.2$ & 0.650 \\
\hline Consequences $^{\mathrm{a}}$ & & $5.5 \pm 3.4$ & & $5.2 \pm 2.9$ & 0.568 \\
\hline Timeline $^{\mathrm{a}}$ & & $8.6 \pm 2.1$ & & $8.5 \pm 2.1$ & 0.831 \\
\hline Personal control & & $6.1 \pm 2.6$ & & $6.2 \pm 2.2$ & 0.815 \\
\hline Treatment control $^{a}$ & & $7.3 \pm 2.1$ & & $7.6 \pm 2.3$ & 0.482 \\
\hline Identity & & $4.9 \pm 2.8$ & & $4.6 \pm 2.9$ & 0.566 \\
\hline Concern $^{\mathrm{a}}$ & & $8.5 \pm 2.0$ & & $8.6 \pm 1.8$ & 0.761 \\
\hline Understanding ${ }^{\mathrm{a}}$ & & $7.4 \pm 1.9$ & & $6.9 \pm 2.4$ & 0.420 \\
\hline Emotional response $\mathrm{e}^{\mathrm{a}}$ & & $3.2 \pm 2.6$ & & $2.8 \pm 2.7$ & 0.316 \\
\hline MOS-social support ${ }^{\mathrm{a}}$ & 57 & & 50 & & \\
\hline Total score & & $84.3 \pm 14.7$ & & $85.5 \pm 15.2$ & 0.637 \\
\hline Emotional/informational support ${ }^{\mathrm{a}}$ & & $33.0 \pm 6.4$ & & $33.7 \pm 6.6$ & 0.434 \\
\hline Tangible support ${ }^{\mathrm{a}}$ & & $18.3 \pm 2.3$ & & $18.3 \pm 2.4$ & 0.776 \\
\hline Affectionate support ${ }^{\mathrm{a}}$ & & $13.1 \pm 2.7$ & & $13.4 \pm 2.4$ & 0.809 \\
\hline Positive social interaction ${ }^{\mathrm{a}}$ & & $12.1 \pm 2.8$ & & $12.2 \pm 3.0$ & 0.706 \\
\hline DKQ & 55 & $13.4 \pm 4.7$ & 45 & $12.6 \pm 5.0$ & 0.397 \\
\hline WHOQOL-BREF & 57 & & 47 & & \\
\hline Domain I: Physical health & & $12.7 \pm 3.5$ & & $12.3 \pm 3.3$ & 0.565 \\
\hline Domain 2: Psychological ${ }^{a}$ & & $14.3 \pm 2.8$ & & $\mid 4.1 \pm 2.8$ & 0.796 \\
\hline Domain 3: Social relationship & & $14.8 \pm 3.3$ & & $14.0 \pm 3.4$ & 0.212 \\
\hline Domain 4: Environment & & $15.4 \pm 2.7$ & & $15.8 \pm 2.6$ & 0.522 \\
\hline
\end{tabular}

Notes: Data presented as mean \pm standard deviation unless stated otherwise. ${ }^{*} P>0.05$ (NS) using independent $t$-test (two tailed). ${ }^{a}$ Analyzed using Mann-Whitney $U$-test. Abbreviations: BMI, body mass index; B-IPQ, Brief-IIness Perception Questionnaire; DKQ, Diabetes Knowledge Questionnaire; GDS, Geriatric Depression Scale; IADL, instrumental activities of daily living; HbAIC, hemoglobin AIC; MoCA, Montreal Cognitive Assessment; MOS, Medical Outcome Study; N/A, not applicable; NS, not significant; SNAQ, simplified nutritional appetite questionnaire; WHOQoL-BREF, World Health Organization Quality of Life-BREF.

Table 3 Multiple linear regression model to predict quality of life $(n=7 \mathrm{I})$

\begin{tabular}{|c|c|c|c|c|c|}
\hline Variables & $T$ & B & $P$-value & $R^{2}$ & {$[d f] F$} \\
\hline \multicolumn{6}{|l|}{ WHOQoL (physical health) } \\
\hline Modified Barthel Index & 5.590 & 0.495 & 0.000 & 0.633 & {$[3,67] 38.462$} \\
\hline GDS & -2.740 & -0.258 & 0.008 & & \\
\hline SNAQ & 2.704 & 0.228 & 0.009 & & \\
\hline \multicolumn{6}{|l|}{ WHOQoL (psychological) } \\
\hline GDS & -6.624 & -0.624 & 0.000 & 0.558 & {$[2,68] 42.953$} \\
\hline IADL & 2.202 & 0.202 & 0.034 & & \\
\hline \multicolumn{6}{|c|}{ WHOQOL (social relationship) } \\
\hline MOS-social support & 6.506 & 0.562 & 0.000 & 0.539 & {$[2,68] 39.763$} \\
\hline The MoCA & 3.850 & 0.332 & 0.000 & & \\
\hline \multicolumn{6}{|l|}{ WHOQoL (environment) } \\
\hline MOS-social support & 6.338 & 0.573 & 0.000 & 0.496 & {$[2,68] 33.403$} \\
\hline The MoCA & 3.007 & 0.272 & 0.004 & & \\
\hline
\end{tabular}

Notes: Adjusted for WHOQoL (physical health): SNAQ, iron intake (mg), MoCA, GDS, B-IPQ, modified Barthel Index, and IADL. Adjusted for WHOQoL (psychological): MoCA, GDS, B-IPQ, B-IPQ (treatment control), B-IPQ (concern), IADL, and MOS-Social Support. Adjusted for WHOQoL (social relationship): MoCA, GDS, B-IPQ (treatment control), B-IPQ (concern), B-IPQ (understanding), IADL, and MOS-social support. Adjusted for WHOQoL (environment): MoCA, GDS, B-IPQ, B-IPQ (concern), IADL, MOS-social support, and DKQ. $P<0.05$ significant using multiple linear regression.

Abbreviations: B-IPQ, Brief-IIIness Perception Questionnaire; DKQ, Diabetes Knowledge Questionnaire; GDS, Geriatric Depression Scale; IADL, instrumental activities of daily living; MoCA, Montreal Cognitive Assessment; MOS, Medical Outcome Study; SNAQ, simplified nutritional appetite questionnaire; WHOQoL, World Health Organization Quality of Life. 
low finance, ${ }^{41,46}$ and lack of social support, ${ }^{45,47,48}$ which need to be considered prior to diagnosis and treatment.

The majority of patients $(83 \%)$ in this study have MCI, and the elderly women in this study are more prone to experience these problems. ${ }^{49} \mathrm{MCI}$ is common among the elderly, ${ }^{9}$ and diabetes is one of the most common predictors of cognitive impairment ${ }^{50-52}$ that eventually leads to dementia. ${ }^{53} \mathrm{MCI}$ among elderly is also common among the clinic attendees and is strongly associated with their low education level. ${ }^{54}$ However, there is a high probability that results might be affected by unstable emotional state and undesirable health condition of the patients during the interview session.

Only $36.4 \%$ of patients in this study were totally ADL independent. This shows that the level of physical disability and functional limitation are much higher than the community-dwelling elderly patients. ${ }^{3,55}$ Hospitalization or restricted activities caused by illnesses or injuries illustrate a significant association with disability in essential ADLs for elderly despite the presence of physical frailty. ${ }^{56}$

Both male and female patients in this study had good social support. It was reported that lack of social support is a strong independent predictor of mortality among elderly with chronic disease. ${ }^{57-60}$ Moreover, a spouse provided the most comprehensive and comforting support to patients. ${ }^{61}$ Social support also plays a significant role to the quality of life of Malaysian elderly. ${ }^{13}$

Global assessment that only consists of one question describing the overall quality of life is not able to identify the underlying dimension contributing to specific domain of quality of life. ${ }^{62}$ Thus, it is important to employ multidimensional assessment of quality of life, which assesses several dimensions, including physical, psychological, and social relationships and the environmental well-being ${ }^{63}$ of the targeted population.

This study showed that the psychological factors, such as depression, negatively affect physical health and psychological aspects of the quality of life. A number of studies suggested that people with diabetes mellitus have higher levels of psychological disturbance, such as depression, ${ }^{4,64,65}$ which consequently affects their quality of life. ${ }^{66}$

This study also showed that physical functioning indicated by the level of independency and IADL affects physical health and psychological domains of the quality of life, respectively. In addition, depression can be affected by physical impairment ${ }^{67}$ and elderly with diabetes are usually more restricted in mobility and often lack in autonomy of IADL, resulting in poor quality of life. ${ }^{66}$ Also, the effect of physical activity on the quality of life is less substantial when the person is already functioning well. ${ }^{68}$
This study has also proven that appetite is a positive predictor for physical health aspect of the quality of life. A lack of appetite related to aging alters certain aspects of nutrition that lead to changes in the quality of life. ${ }^{69}$ This matter must be addressed because deterioration of $>5 \%$ body weight within 6 months among hospitalized elderly can contribute to life-threatening complications. ${ }^{70}$ Therefore, appetite aspect should be thoroughly considered before recommending any medical interventions to patients during their hospitalization.

This study examined the social support received by the patient as a whole and found that social support plays a major role in predicting social relationships and environmental aspects of the quality of life among geriatric patients with diabetes mellitus. Among elderly in rural communities, social support in the form of emotional and informational support is a significant factor related to the quality of life. ${ }^{13}$ Although there were different types of social support, such as emotional support, instrumental support, and informational support, they were equally essential depending on individual and situational differences and also on the presence of stressors. ${ }^{71}$ For example, physical impairment increases the needs for social support, and it can lead to either life satisfaction or depression. ${ }^{67}$

In addition, this study found that cognitive function plays an important role in predicting social relationships and environmental aspects of the quality of life among geriatric patients with diabetes mellitus. A few authors particularly focus on the direct association between cognitive function and quality of life. A previous study found that the quality of life is influenced by both physical and psychological factors, concentration, and memory. ${ }^{72}$ A significantly higher intelligence and memory quotient were reported in patients with a restored or improved quality of life than in patients with a deteriorated quality of life. ${ }^{73}$ Furthermore, it was reported that cognitive impairment is also an important predictor of long-term depressive syndrome and quality of life specifically for those with preexisting diabetes mellitus. ${ }^{74}$

\section{Conclusion}

The findings showed that physical functioning, appetite, cognitive status, depression, and social support play an important role in the quality of life among hospitalized geriatric patients with diabetes mellitus. These findings provide information to health service providers to implement intervention programs, particularly after discharge for caregivers and patients to increase their quality of life. 


\section{Limitations}

This study took place at patients' bedsides in the ward. Interviews had to be conducted in a few sessions to complete all parts of questionnaires due to inevitable circumstances, such as patients' unfavorable health condition, emotional disturbance, and interruptions for medical procedures. Thus, shorter, simpler, and suitable questionnaires for the clinical setting are needed for future studies.

\section{Acknowledgment}

The authors would like to thank the respondents involved in this study.

\section{Disclosure}

The authors report no conflicts of interest in this work.

\section{References}

1. Ministry of Health Malaysia. Country Health Plan. 10th Malaysia Plan (2011-2015). Putrajaya: Ministry of Health Malaysia; 2010.

2. Vischer UM, Perrenoud L, Genet C, Ardigo S, Registe-Rameau Y, Herrmann F. The high prevalence of malnutrition in elderly diabetic patients: implications for anti-diabetic drug treatments. Diabet Med. 2010;27(8):918-924.

3. Hairi NN, Bulgiba A, Cumming RG, Naganathan V, Mudla I. Prevalence and correlates of physical disability and functional limitation among community dwelling older people in rural Malaysia, a middle income country. BMC Public Health. 2010;10(1):492.

4. Anderson RJ, Freedland KE, Clouse RE, Lustman PJ. The prevalence of comorbid depression in adults with diabetes a meta-analysis. Diabetes Care. 2001;24(6):1069-1078.

5. Larsson J, Unosson M, Ek AC, Nilsson L, Thorslund S, Bjurulf P. Effect of dietary supplement on nutritional status and clinical outcome in 501 geriatric patients - a randomised study. Clin Nutr. 1990;9(4): 179-184.

6. Massler M. Geriatric nutrition: the role of taste and smell in appetite. J Prosthet Dent. 1980;43(3):247-250.

7. Chernoff R. Geriatric Nutrition. Burlington, MA: Jones \& Bartlett Publishers; 2013.

8. Mowe M, Bøhmer T, Kindt E. Reduced nutritional status in an elderly population $(>70 \mathrm{y})$ is probable before disease and possibly contributes to the development of disease. Am J Clin Nutr. 1994;59(2):317-324.

9. Lee LK, Suzana S, Chin A-V. Predicting comorbidities, nutritional status, and neuropsychological performance of depressed and nondepressed geriatric communities: a comparative study. Int $J$ Gerontol. 2012;6(4):278-284.

10. Greenglass E, Fiksenbaum L, Eaton J. The relationship between coping, social support, functional disability and depression in the elderly. Anxiety Stress Coping. 2006;19(1):15-31.

11. Moussavi S, Chatterji S, Verdes E, Tandon A, Patel V, Ustun B. Depression, chronic diseases, and decrements in health: results from the World Health Surveys. Lancet. 2007;370(9590):851-858.

12. Patric J, Ryan J, Kenneth E, Mary D, Robert M, Ray E. Depression and poor glycemic control. Diabetes Care. 2000;23:934-942.

13. Norhayati I, Normah CD, Mahadir A, et al. Relationships between social support and depression, and quality of life of the elderly in a rural community in Malaysia. Asia-Pac Psychiatry. 2013;5(S1):59-66.

14. Robert D, Pat J, Laura J. Diabetes, depression and quality of life. Diabetes Care. 2004;27(5):1066-1070.

15. Roos NP, Havens B. Predictors of successful aging: a twelve-year study of Manitoba elderly. Am J Public Health. 1991;81(1):63-68.
16. Matthews SJ, Lancaster JW. Urinary tract infections in the elderly population. Am J Geriatr Pharmacother. 2011;9(5):286-309.

17. Solheim J, Kværner KJ, Falkenberg ES. Daily life consequences of hearing loss in the elderly. Disabil Rehabil. 2011;33(23-24):2179-2185.

18. Davenport RD, Vaidean GD, Jones CB, et al. Falls following discharge after an in-hospital fall. BMC Geriatr. 2009;9:53.

19. Inouye SK, Studenski S, Tinetti ME, Kuchel GA. Geriatric syndromes: clinical, research, and policy implications of a core geriatric concept. J Am Geriatr Soc. 2007;55(5):780-791.

20. Dwyer J. Nutritional problems of elderly minorities. Nutr Rev. 1994; 52(8 pt 2):S24-S27.

21. Beeney LJ, Dunn SM. Knowledge improvement and metabolic control in diabetes education: approaching the limits? Patient Educ Couns. 1990; 16(3):217-229.

22. Dunn SM, Beeney LJ, Hoskins PL, Turtle JR. Knowledge and attitude change as predictors of metabolic improvement in diabetes education. Soc Sci Med. 1990;31(10):1135-1141.

23. Bruce DG, Davis WA, Cull CA, Davis TM. Diabetes education and knowledge in patients with type 2 diabetes from the community: the Fremantle Diabetes Study. J Diabetes Complications. 2003;17(2): $82-89$.

24. Cohen HJ, Feussner JR, Weinberger M, et al. A controlled trial of inpatient and outpatient geriatric evaluation and management. $N$ Engl J Med. 2002;346(12):905-912.

25. Wilson M-MG, Thomas DR, Rubenstein LZ, et al. Appetite assessment: simple appetite questionnaire predicts weight loss in communitydwelling adults and nursing home residents. Am J Clin Nutr. 2005;82(5): 1074-1081.

26. Shahar S, Earland J, Abdulrahman S. Validation of a dietary history questionnaire against a 7-D weighed record for estimating nutrient intake among rural elderly Malays. Malays $J$ Nutr. 2000;6(1):33-44.

27. Nasreddine ZS, Phillips NA, Bédirian V, et al. The Montreal Cognitive Assessment, MoCA: a brief screening tool for mild cognitive impairment. J Am Geriatr Soc. 2005;53(4):695-699.

28. Yesavage JA, Brink T, Rose TL, et al. Development and validation of a geriatric depression screening scale: a preliminary report. J Psychiatr Res. 1983;17(1):37-49.

29. Broadbent E, Petrie KJ, Main J, Weinman J. The brief illness perception questionnaire. J Psychosom Res. 2006;60(6):631-637.

30. Shah S, Vanclay F, Cooper B. Improving the sensitivity of the Barthel Index for stroke rehabilitation. J Clin Epidemiol. 1989;42(8): 703-709.

31. Lawton MP, Brody EM. Assessment of older people: self-maintaining and instrumental activities of daily living. Gerontologist. 1969;9(3 pt 1): 179-186.

32. Sherbourne CD, Stewart AL. The MOS social support survey. Soc Sci Med. 1991;32(6):705-714.

33. World Health Organization. WHOQOL-BREF: introduction, administration, scoring and generic version of the assessment: field trial version, 1996. Health DoM. Geneva: World Health Organization; 1996:16.

34. National Coordinating Committee on Food and Nutrition. Recommended Nutrient Intakes for Malaysia. Putrajaya: Ministry of Health Malaysia; 2005.

35. Suzana S, Zuriati I, Afaf Ruhi Abdul F, Suriah A, Siti Nur' Asyura A. A multidimensional assessment of nutritional and health status of rural elderly Malaysia. Asia Pac J Clin Nutr. 2007;16(2):346-353.

36. Sullivan DH, Sun S, Walls RC. Protein-energy undernutrition among elderly hospitalized patients: a prospective study. JAMA. 1999;281(21): 2013-2019.

37. Suzana S, Chee KY, Chik WCPW. Food intakes and preferences of hospitalised geriatric patients. BMC Geriatr. 2002;2(1):3.

38. Dupertuis Y, Kossovsky M, Kyle U, Raguso C, Genton L, Pichard C. Food intake in 1707 hospitalised patients: a prospective comprehensive hospital survey. Clin Nutr. 2003;22(2):115-123.

39. Sherina MS, Nor Afiah MZ, Shamsul Azhar S. Factors associated with depression among elderly patients in a primary health care clinic in Malaysia. Asia Pac Fam Med. 2003;2(3):148-152. 
40. Sherina M, Rampal L, Mustaqim A. The prevalence of depression among the elderly in Sepang, Selangor. Med J Malaysia. 2004;59(1):45-49.

41. Imran A, Azidah A, Asrenee A, Rosediani M. Prevalence of depression and its associated factors among elderly patients in outpatient clinic of Universiti Sains Malaysia Hospital. Med J Malaysia. 2009;64(2): 134-139.

42. Koenig HG. Depression in hospitalized older patients with congestive heart failure. Gen Hosp Psychiatry. 1998;20(1):29-43.

43. Koenig HG, George LK, Peterson BL. Religiosity and remission of depression in medically ill older patients. Am J Psychiatry. 1998;155(4): 536-542.

44. Glei DA, Goldman N, Chuang Y-L, Weinstein M. Do chronic stressors lead to physiological dysregulation? Testing the theory of allostatic load. Psychosom Med. 2007;69(8):769-776.

45. Lim LL, Ng TP. Living alone, lack of a confidant and psychological well-being of elderly women in Singapore: the mediating role of loneliness. Asia-Pac Psychiatry. 2010;2(1):33-40.

46. Koenig HG, Meador KG, Cohen HJ, Blazer DG. Depression in elderly hospitalized patients with medical illness. Arch Intern Med. 1988; 148(9):1929-1936.

47. Chen R, Wei L, Hu Z, Qin X, Copeland JR, Hemingway H. Depression in older people in rural China. Arch Intern Med. 2005;165(17): 2019-2025.

48. Salimah O, Rahmah M, Rosdinom R, Azhar SS. A case control study on factors that influence depression among the elderly in Kuala Lumpur Hospital and Universiti Kebangsaan Malaysia Hospital. Med J Malaysia. 2008;63(5):395-400.

49. Gregg EW, Yaffe K, Cauley JA, et al. Is diabetes associated with cognitive impairment and cognitive decline among older women? Arch Intern Med. 2000;160(2):174-180.

50. Arvanitakis Z, Wilson RS, Bienias JL, Evans DA, Bennett DA. Diabetes mellitus and risk of Alzheimer disease and decline in cognitive function. Arch Neurol. 2004;61(5):661-666.

51. Luchsinger JA, Reitz C, Patel B, Tang M-X, Manly JJ, Mayeux R. Relation of diabetes to mild cognitive impairment. Arch Neurol. 2007;64(4): 570-575.

52. Cheng G, Huang C, Deng H, Wang H. Diabetes as a risk factor for dementia and mild cognitive impairment: a meta-analysis of longitudinal studies. Intern Med J. 2012;42(5):484-491.

53. Yaffe K, Blackwell T, Kanaya A, Davidowitz N, Barrett-Connor E, Krueger K. Diabetes, impaired fasting glucose, and development of cognitive impairment in older women. Neurology. 2004;63(4): 658-663.

54. Razali R, Baharudin A, Jaafar NRN, Sidi H, Rosli AH. Factors associated with mild cognitive impairment among elderly patients attending medical clinics in Universiti Kebangsaan Malaysia Medical Centre. Sains Malays. 2012;41(5):641-647.

55. Lopes MA, Hototian SR, Bustamante SE, et al. Prevalence of cognitive and functional impairment in a community sample in Ribeirão Preto, Brazil. Int J Geriatr Psychiatry. 2007;22(8):770-776.
56. Gill TM, Allore HG, Holford TR, Guo Z. Hospitalization, restricted activity, and the development of disability among older persons. JAMA. 2004;292(17):2115-2124.

57. Berkman LF. The role of social relations in health promotion. Psychosom Med. 1995;57(3):245-254.

58. Krumholz HM, Butler J, Miller J, et al. Prognostic importance of emotional support for elderly patients hospitalized with heart failure. Circulation. 1998;97(10):958-964.

59. Zhang X, Norris SL, Gregg EW, Beckles G. Social support and mortality among older persons with diabetes. Diabetes Educ. 2007;33(2): 273-281.

60. Berkman LF, Leo-Summers L, Horwitz RI. Emotional support and survival after myocardial infarction: a prospective, population-based study of the elderly. Ann Intern Med. 1992;117(12):1003-1009.

61. Johnson CL. Dyadic family relations and social support. Gerontologist. 1983;23(4):377-383.

62. Testa MA, Simonson DC. Assessment of quality-of-life outcomes. N Engl J Med. 1996;334(13):835-840.

63. Power M, Bullinger M, Harper A. The World Health Organization WHOQOL-100: tests of the universality of quality of life in 15 different cultural groups worldwide. Health Psychol. 1999;18(5):495-505.

64. Gavard JA, Lustman PJ, Clouse RE. Prevalence of depression in adults with diabetes: an epidemiological evaluation. Diabetes Care. 1993; 16(8):1167-1178.

65. Lustman P, Griffith L, Clouse R. Depression in adults with diabetes. Paper presented at: Seminars in Clinical Neuropsychiatry 1997.

66. Bourdel-Marchasson I, Dubroca B, Manciet G, Decamps A, Emeriau JP, Dartigues JF. Prevalence of diabetes and effect on quality of life in older French living in the community: the PAQUID Epidemiological Survey. J Am Geriatr Soc. 1997;45(3):295-301.

67. Newsom JT, Schulz R. Social support as a mediator in the relation between functional status and quality of life in older adults. Psychol Aging. 1996;11(1):34-44.

68. Rejeski WJ, Brawley LR, Shumaker SA. Physical activity and health-related quality of life. Exerc Sport Sci Rev. 1996;24(1): 71-108.

69. Amarantos E, Martinez A, Dwyer J. Nutrition and quality of life in older adults. J Gerontol A Biol Sci Med Sci. 2001;56(suppl 2):54-64.

70. Sullivan DH, Bopp MM, Roberson PK. Protein-energy undernutrition and Life-threatening complications among the hospitalized elderly. J Gen Intern Med. 2002;17(12):923-932.

71. Helgeson VS. Social support and quality of life. Qual Life Res. 2003; 12(1):25-31.

72. Ahlsiö B, Britton M, Murray V, Theorell T. Disablement and quality of life after stroke. Stroke. 1984;15(5):886-890.

73. Niemi M-L, Laaksonen R, Kotila M, Waltimo O. Quality of life 4 years after stroke. Stroke. 1988;19(9):1101-1107.

74. Nys G, Van Zandvoort M, Van Der Worp H, et al. Early cognitive impairment predicts long-term depressive symptoms and quality of life after stroke. J Neurol Sci. 2006;247(2):149-156.
Clinical Interventions in Aging

\section{Publish your work in this journal}

Clinical Interventions in Aging is an international, peer-reviewed journal focusing on evidence-based reports on the value or lack thereof of treatments intended to prevent or delay the onset of maladaptive correlates of aging in human beings. This journal is indexed on PubMed Central, MedLine,
CAS, Scopus and the Elsevier Bibliographic databases. The manuscript management system is completely online and includes a very quick and fair peer-review system, which is all easy to use. Visit http://www.dovepress. $\mathrm{com} /$ testimonials.php to read real quotes from published authors. 